\title{
Fostamatinib: a review of its clinical efficacy and safety in the management of chronic adult immune thrombocytopenia
}

\author{
Adrian Newland ${ }^{*}, 1$ (iD) \& Vickie McDonald ${ }^{2}$ \\ ${ }^{1}$ Academic Haematology Unit, Blizard Institute, Barts \& The London School of Medicine \& Dentistry, Queen Mary Institute of \\ London, London, UK \\ ${ }^{2}$ Department of Haematology, The Royal London Hospital, Barts Health NHS Trust, London, UK \\ *Author for correspondence: Tel.: +44 (0) 203246 0338; a.c.newland@qmul.ac.uk
}

\begin{abstract}
Management of chronic immune thrombocytopenia (ITP) is going through a transition, with the main driving forces being a better understanding of the disease, recognition that platelet count is less important than bleeding symptoms, and the availability of new therapies. The heterogeneity of chronic ITP makes treatment challenging, and highlights the need for a personalized approach. A key aspect of tailored treatment is the availability of agents to target specific underlying pathophysiological mechanisms. In this review, we examine the evidence for orally bioavailable fostamatinib and its active moiety, tamatinib (R406), which has been approved for the treatment of chronic adult ITP. Fostamatinib inhibits FcR-triggered, Syk-dependent cytoskeletal rearrangement during phagocytosis and, as such, represents an active therapy targeting a previously unexplored mechanism of ITP pathogenesis.
\end{abstract}

First draft submitted: 29 July 2020; Accepted for publication: 16 September 2020; Published online: 7 October 2020

Keywords: fostamatinib • immune thrombocytopenia • ITP • spleen tyrosine kinase $\bullet$ targeted therapy • tyrosine kinase inhibitor

Immune thrombocytopenia (ITP) is an autoantibody-mediated heterogeneous disorder characterized by a low platelet count $(<100,000 / \mu \mathrm{l})$ in the absence of other causes for the bleeding [1]. At presentation it can be asymptomatic, mildly symptomatic (mucocutaneous lesions/bleeding) or serious/life-threatening (intracranial and gastrointestinal bleeding with complications) [2-4]. Estimates of the average annual prevalence of ITP have varied relatively widely, with Kistangari \& McCrae reporting a range of 4 to 23.6 per 100,000 person/year in adults [5]. In individual studies, rates for the prevalence of ITP per 100,000 included: 9.5 [6]; 8.1 in children and 12.1 in adults [7]; and 23.6 in adults (with annual rates of 7.1 and 9.5/100,000 reported in 2 separate years) [8]. Overall, the incidence of ITP has generally been reported to be between two and four cases per 100,000 person-years [3,5,9]. In adults, the prevalence of ITP increases with age and may be slightly higher in women of reproductive age and older males $[5,9,10]$. The inflammatory biology and relapse/refractory nature of ITP pose both physical and psychosocial challenges to patients who have to live with the disease for prolonged periods. As such, ITP has a negative impact on the patient's quality of life (QoL), particularly with respect to physical functioning and mental health [11].

ITP is a chronic heterogeneous disease and medical therapy is rarely curative [5]. Initial treatment comprises corticosteroids with or without intravenous immunoglobulin (IVIg) or intravenous anti-D immune globulin (IVanti-D). However, the majority of patients will eventually require alternative therapy as a result of poor tolerability or relapse [12]. This has resulted in an unmet need for alternative therapeutic options and the evaluation of a range medical therapies, as alternatives to splenectomy, including rituximab, the thrombopoietin-receptor agonists (TPO-RA) eltrombopag, avatrombopag and romiplostim, and fostamatinib, which is a recently approved spleen tyrosine kinase (Syk) inhibitor and the focus of this review.

The Syk signaling pathway has emerged as a potential new target for treatment of autoimmune diseases, including ITP. As platelet destruction in ITP is mediated by Syk-dependent phagocytosis of Fc $\gamma$ R-bound platelets [13], Syk inhibition represents a promising approach to the management of ITP. Here, we update the findings from our

Future Medicine 


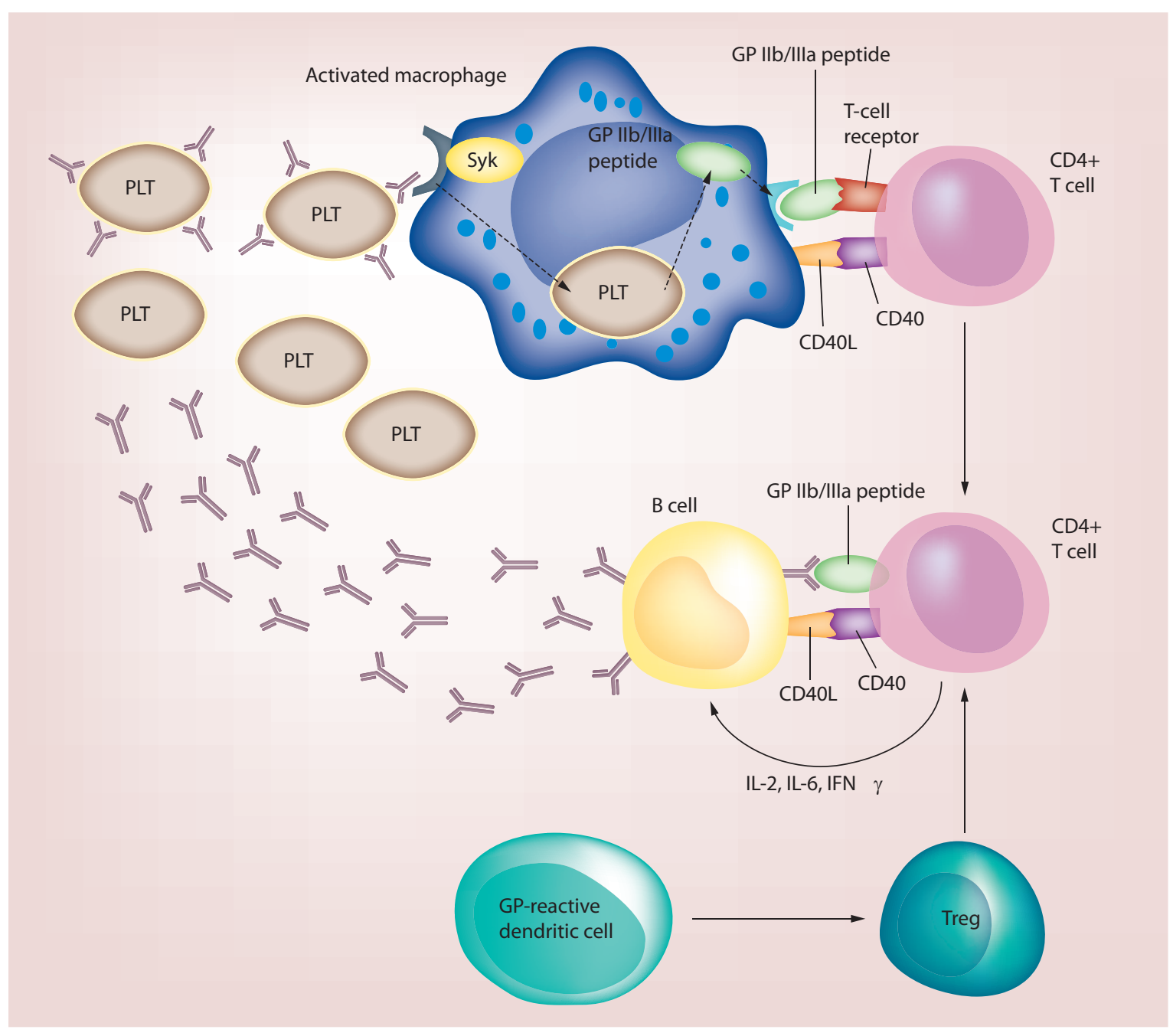

Figure 1. Pathogenesis of immune thrombocytopenia. ITP is an autoimmune disease caused by antiglycoprotein autoantibodies that deplete platelets via destruction and inhibition of megakaryocyte production of new platelets. Autoantibody-coated platelets bind to antigen-presenting cells through the FcR, leading to Syk-dependent platelet engulfment and destruction by macrophages. Activated macrophages and dendritic cells induce proliferation of platelet-reactive CD4+ Th cells and Treg cells, which together amplify the production of antiplatelet antibodies from activated B cells.

Republished with permission of Future Medicine Ltd [14]; permission conveyed through Copyright Clearance Center, Inc.

GP: Glycoprotein; ITP: Immune thrombocytopenia; PLT: Platelet.

previous review which evaluated much of the preclinical and early clinical data on fostamatinib [14] and focus on the clinical evidence for this novel orally administered pro-drug which is approved as a treatment for chronic ITP in adults. For this narrative review, a search of PubMed up to 22 June 2020 using the search term 'fostamatinib' $(\mathrm{n}=178)$ was conducted to identify relevant articles assessing the clinical use of fostamatinib in chronic/persistent ITP in adults, and this was augmented with articles known to the authors and relevant to this topic.

\section{Pathogenesis of ITP}

ITP is believed to occur as a consequence of defects in immune tolerance. Two major mechanisms contribute to the development of ITP: increased platelet destruction and insufficient platelet production. The pathophysiology of the disease is complex and not fully understood, although both antibody-mediated and/or T cell-mediated platelet destruction are key processes (Figure 1). A common view is that autoantibodies are produced which bind to glycoproteins on the surface of platelets and mark them for phagocytic breakdown in the spleen and liver 
through an interaction with $\mathrm{F}_{\mathrm{c}} \gamma$ receptors $[2,3,14]$. In addition, autoantibodies have been reported to increase complement-mediated or desialylation-induced platelet destruction, and also inhibit megakaryocyte production of new platelets [3]. However, as many as $30-40 \%$ of patients with ITP have no detectable antibodies and other mechanisms must be involved [2].

As noted in our previous review, alterations in B- and T-cell tolerance can result in clonal expansion of plateletreactive antibodies that arise through somatic mutations and these changes in tolerance can occur centrally, during differentiation, or peripherally. The latter is thought to result in a platelet-specific disorder (primary ITP) that is more sensitive to therapy [15]. Furthermore, a skewed Th1/Th2 ratio with increased levels of IFN- $\gamma$, IL-2 and IL-17, and decreased peripheral Th2 and Treg cells have also been observed in patients with primary ITP [16-18]. These changes favor the survival of autoreactive T-cell clones and drive T-cell-dependent, antigen-driven clonal expansion and somatic mutations of autoantibodies in ITP [19].

Autoantibodies initially target platelet surface glycoproteins, primarily GPIIb/IIIa (integrin $\alpha \operatorname{IIb} \beta 3$ ) and GPIb/IX [20], but epitope spreading enables the production of antibodies against additional targets [21]. Following binding of autoantibodies to the platelet surface they are cleared by splenic macrophages through Fc $\gamma$ R-mediated phagocytosis, although alternative mechanisms for platelet clearance (e.g., complement-dependent lysis) have been reported [22]. More recently, GPV has also been shown to be an immune target in ITP and anti-GPV autoantibodies are of clinical relevance since they were able to remove platelets from the circulation [23]. In addition, abnormalities in megakaryocyte proliferation and differentiation attributed to the presence of autoantibodies may also diminish platelet production [24].

The current therapeutic approaches for the treatment of ITP have been developed to target distinct events that occur along the pathogenetic pathway, either through inhibition of immunological events that promote destruction or inhibit development of platelets (e.g. steroids, intravenous immunoglobulin (IVIg), anti-D, fostamatinib, rituximab, immunosuppressive agents) or by promoting the production of new platelets (e.g. TPO-RA).

\section{Treatment of adults with chronic ITP}

The management of adult patients with persistent/chronic ITP has markedly changed over the last 50 years and is currently going through a transition, with the main driving forces being a greater understanding of the disease per se, recognition that platelet count is less important than overall bleeding symptoms, and the availability of new therapies $[12,25,26]$. ITP is a heterogeneous disease and presentation can vary widely, particularly with regard to platelet count and level of bleeding, thus necessitating an individualized approach to treatment [25]. Factors impacting on treatment decisions include: extent of bleeding, age, comorbidities predisposing to bleeding, disease stage/duration and severity, activity/lifestyle, potential adverse effects, patient-related factors such as well-being/QoL, fatigue and expectations/concerns [12]. The numerous changes in treatment practices that have taken place in the last decade are reflected in recent guidance/guidelines documents, including those from the American Society of Hematology (ASH) [26], as well as an updated International Consensus Report produced by a global panel of expert investigators using clinical best evidence and expert opinion [12].

The recommended treatment goals in these evidence-based consensus reports include: treatment to prevent severe bleeding, maintenance of a target platelet level of $>20-30 \times 10^{9} / 1$ (at least for symptomatic patients), minimal treatment-related toxicity and improvement in the individual's QoL [12]. Figure 2 provides and overview of the treatment approach advocated in the International Consensus Report based upon a thorough review of clinical best evidence up to 2018 augmented with the expert opinion of the panel members [12].

For newly diagnosed patients, corticosteroids such as prednisone, prednisolone, methylprednisolone and dexamethasone, which are easily administered and relatively inexpensive, are the mainstay for the initial management of adults with ITP. IVIg or IV-anti-D may be appropriate initial treatment options in patients unresponsive to corticosteroids, and in those who have contraindications to steroid therapy (patients with insulin-dependent diabetes, uncontrolled diabetes, active infection and psychiatric disorders) or require a more rapid response [12]. These agents can be used to increase platelet count rapidly in emergency situations and are not intended for long-term use because of limited duration of response and potential toxicity. Other than a small number of patients who can be maintained on daily low doses of steroids, the majority of patients with ITP will eventually require alternative therapy. The agents with the most robust evidence supporting their use the treatment of ITP include rituximab, the thrombopoietin-receptor agonists (TPO-RA) eltrombopag, avatrombopag and romiplostim, and the Syk inhibitor fostamatinib [Figure 2]. Agents with less robust evidence include azathioprine, cyclosporin, cyclophosphamide, mycophenolate, etc. Splenectomy, which was previously considered a second-line approach is now considered to 

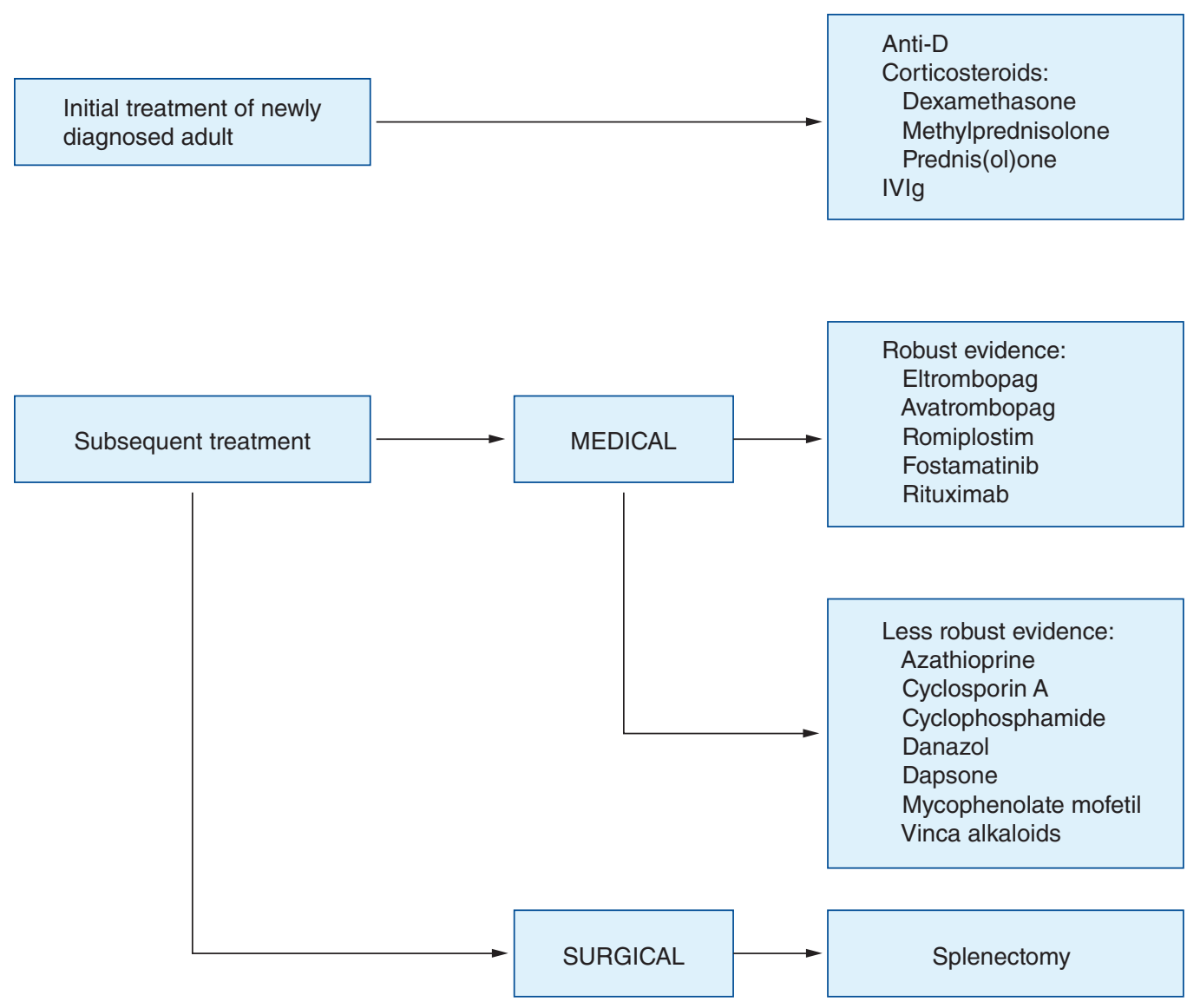

Figure 2. Overview of therapies available for the treatment of immune thrombocytopenia as advocated in the International Consensus Report.

Republished with permission of American Society of Hematology (ASH) [12]; permission conveyed through Copyright Clearance Center, Inc.

be 'Subsequent therapy: surgical' and it is generally recommended to wait $\geq 12$ to 24 months after diagnosis before performing the splenectomy because of the possibility of stabilization or remission. Steroids, IVIg, TPO-RAs or other effective therapies may be used during this period to help increase platelet counts prior to splenectomy. It is also recommended that predictive studies assessing potential response using Indium labelled platelets are considered before surgery [12].

\section{Fostamatanib}

\section{Background}

Fostamatinib disodium hexahydrate (R788; Tavalisse ${ }^{\circledR}$, Riegel Pharmaceuticals) has the chemical formula N4-(2,2-dimethyl-4-[(dihydrogenphosphonoxy)methyl]-3-oxo-5-pyrid[1,4] oxazin-6-yl)-5-fluoroN2-(3,4,5trimethyoxy-phenyl)-2,4-pyrimidinediamine disodium hexahydrate. It is an orally bioavailable prodrug that is metabolized to its biologically active form, tamatinib [(R406) N4-2,2-dimethyl-3-oxo-4H-pyrid[1,4] oxazin-6-yl)5-fluoro-N2-(3,4,5-trimethoxyphenyl)-2,4-pyrimidinediamine], a potent and selective small molecule inhibitor of Syk (Figure 3) [14]. R406 has poor aqueous solubility, and fostamatinib was designed as a methylene-phosphate prodrug which is cleaved by alkaline phosphatase at the apical brush-border membranes of intestinal enterocytes to its active moiety [14].

\section{Pharmacology}

Mechanism of action \& pharmacodynamic properties

$\mathrm{R} 406$ is a spleen tyrosine kinase inhibitor with demonstrated activity against Syk and it has been shown to inhibit signal transduction of B-cell receptors and Fc-activating receptors, which play a key role in antibody-mediated 


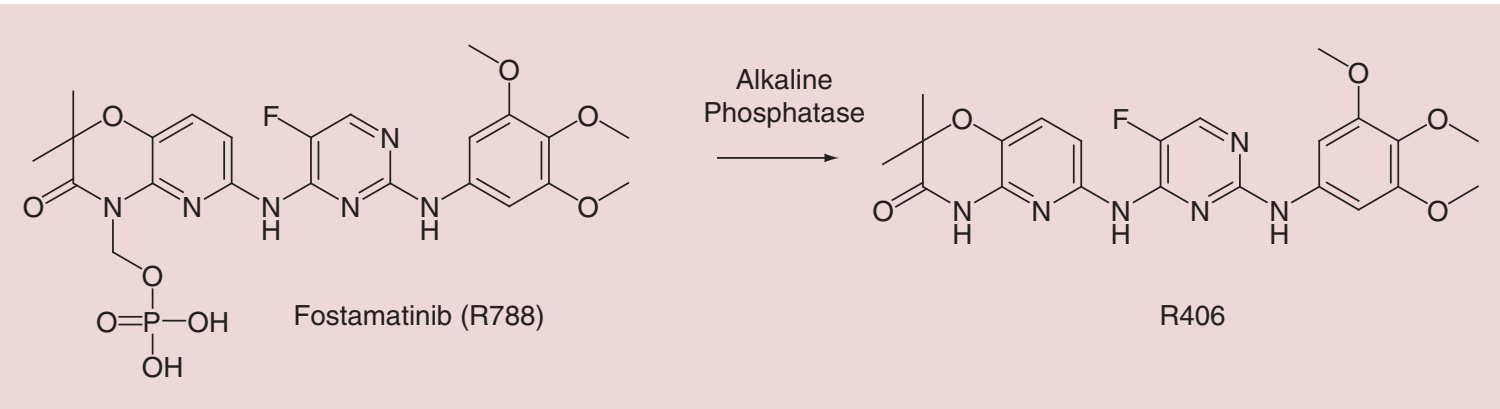

Figure 3. Metabolism of the orally bioavailable prodrug, fostamatinib, to its biologically active form, tamatinib (R406), by alkaline phosphatases at the apical brush-border membranes of intestinal enterocytes.

Republished with permission of Future Medicine Ltd [14]; permission conveyed through Copyright Clearance Center, Inc.

cellular responses. These effects have been explored in autoimmune and inflammatory disease models, and in models of hematological malignancies (e.g., B-cell lymphomas and chronic lymphocytic leukemia), and R406 was found to inhibit or delay the onset of disease progression. In the context of ITP, R406 has been shown to reduce antibody-mediated destruction of platelets. These pharmacodynamic/preclinical studies were covered in greater detail in our previous review and some of the key findings were [14]:

- In vitro R406 inhibited Syk-mediated IgE- and IgG-mediated activation of FcR signaling and FCER-and $\mathrm{FC} \gamma \mathrm{R}$-dependent responses in a number of cell types, and it inhibited degranulation, cytokine production and FcR-mediated antigen internalization in mast cells, TNF- $\alpha$ production induced by Fc $\gamma \mathrm{R}$-cross-linking in macrophages, anti-IgG-induced oxidative burst in TNF $\alpha$-primed neutrophils and FC $\gamma \mathrm{R}$-dependent arachidonic acid release in dendritic cells in response to immune complexes [27,28].

- Inhibition of Syk by R406 inhibited all downstream phosphorylation events of the Syk pathway, including PLC $\gamma 1$, Akt/PKB, Erk, p38 and JNK [27].

- The specificity of R406 for Syk is further supported by observations that the phenotype of R406-treated cells is similar to that observed after siRNA knockdown of Syk in a basophilic cell line [29].

- In platelets, Syk activation occurs through ITAM-containing GPVI (collagen receptor) and certain integrins ( $\alpha$ IIb $\beta 3$; GPIIb/IIIa) and R406-treated mice did not show extended bleeding times compared with vehicle [3032].

- Lack of detrimental effects on platelets was confirmed in studies of R406 in human platelets, with no impairment in platelet aggregation in treated platelets, this is consistent with prior studies showing little to no coagulation defect due to Syk-deficiency or GPVI deficiency [31,33].

- Development of thrombocytopenia and hemolytic anemia was also impeded by fostamatinib in disease models of ITP and warm antibody autoimmune hemolytic anemia [34].

- In animal models where antibodies against platelets and red cells were passively transferred to mice, fostamatinib treatment prevented the development of thrombocytopenia and hemolytic anemia [34].

- Fostamatinib $(25-40 \mathrm{mg} / \mathrm{kg})$ significantly protected mice from developing thrombocytopenia, compared with vehicle only, in a disease model for ITP (mice injected with platelet-targeting anti-integrin $\alpha$-IIb antibodies) [34].

\section{Pharmacokinetics}

The pharmacokinetic properties of fostamatinib and its active metabolite, R406, have been investigated in healthy volunteers (including Japanese subjects), and in patients with renal disease, liver disease, non-Hodgkin lymphoma and rheumatoid arthritis (Table 1) [35-39].

\section{Absorption}

Preclinical studies confirmed that fostamatinib at single oral doses of 10 and $20 \mathrm{mg} / \mathrm{kg}$ was rapidly absorbed and

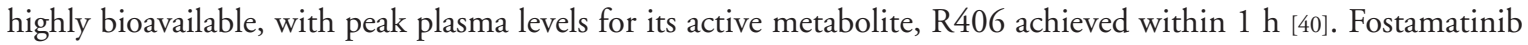
was not detected in plasma samples in this animal model suggesting that it is completely converted to the active metabolite. 
Table 1. Pharmacokinetic parameters for fostamatinib and its biologically active form (R406) in human studies.

\begin{tabular}{|c|c|c|c|c|c|c|c|c|}
\hline \multirow[t]{2}{*}{ Author } & & \multicolumn{6}{|c|}{ Pharmacokinetic parameters for R406 } & \multirow[t]{2}{*}{ Ref. } \\
\hline & & $\mathrm{C}_{\max }(\mathrm{ng} / \mathrm{ml})$ & $t_{\max }(\mathrm{h})$ & AUC (ng/ml·h) & $t_{1 / 2}(h)$ & $\mathrm{CL}(\mathrm{I} / \mathrm{min})$ & $\operatorname{Vd}(\mathbf{l})$ & \\
\hline \multicolumn{9}{|c|}{ Healthy volunteers ( $n=5$ to 6 per group) } \\
\hline \multirow[t]{8}{*}{ Baluom et al. 2013} & $\mathrm{R} 40680 \mathrm{mg}$ & $501 \pm 128$ & $1.3 \pm 0.3$ & $4410 \pm 997$ & $14.5 \pm 3.9$ & $0.32 \pm 0.07$ & $409 \pm 175$ & [35] \\
\hline & $\mathrm{R} 406250 \mathrm{mg}$ & $2030 \pm 489$ & $1.2 \pm 0.3$ & $18,100 \pm 2930$ & $14.9 \pm 3.6$ & $0.24 \pm 0.04$ & $306 \pm 95$ & \\
\hline & $\mathrm{R} 406400 \mathrm{mg}$ & $3410 \pm 745$ & $1.5 \pm 0.5$ & $34,900 \pm 14,600$ & $17.8 \pm 10.6$ & $0.22 \pm 0.09$ & $340 \pm 276$ & \\
\hline & $\mathrm{R} 406500 \mathrm{mg}$ & $3660 \pm 713$ & $1.1 \pm 0.2$ & $29,600 \pm 6270$ & $20.9 \pm 5.8$ & $0.29 \pm 0.06$ & $546 \pm 249$ & \\
\hline & $\mathrm{R} 406600 \mathrm{mg}$ & $3920 \pm 888$ & $1.3 \pm 0.3$ & $36600 \pm 7760$ & $12.9 \pm 5.9$ & $0.29 \pm 0.09$ & $316 \pm 146$ & \\
\hline & Fostamatinib $80 \mathrm{mg}$ & $306 \pm 46$ & $1.1 \pm 0.2$ & $3150 \pm 982$ & $14.8 \pm 4.7$ & $0.45 \pm 0.13$ & $557 \pm 166$ & \\
\hline & Fostamatinib $250 \mathrm{mg}$ & $1140 \pm 122$ & $1.6 \pm 0.4$ & $13,700 \pm 3140$ & $16.0 \pm 2.8$ & $0.32 \pm 0.07$ & $431 \pm 82$ & \\
\hline & Fostamatinib $400 \mathrm{mg}$ & $1220 \pm 317$ & $1.6 \pm 0.4$ & $13,400 \pm 4360$ & $12.1 \pm 2.0$ & $0.54 \pm 0.15$ & $545 \pm 109$ & \\
\hline \multicolumn{9}{|c|}{ Japanese and white subjects ( $n=5$ to 12 per dosage group) } \\
\hline \multirow[t]{5}{*}{ Martin et al. 2016} & Fostamatinib $50 \mathrm{mg}$ & $163 \pm 56$ & 3 & $2170 \pm 308$ & 14.7 & $3.3 \pm 1.2$ & & [36] \\
\hline & Fostamatinib $100 \mathrm{mg}$ & $338 \pm 164$ & 3 & $4150 \pm 1460$ & 19.3 & $3.0 \pm 1.3$ & & \\
\hline & $\begin{array}{l}\text { Fostamatinib } 150 \mathrm{mg} \\
\text { (white subjects) }\end{array}$ & $431 \pm 184$ & 1.5 & $4620 \pm 1390$ & 14.6 & $4.0 \pm 2.4$ & & \\
\hline & Fostamatinib $150 \mathrm{mg}$ & $626 \pm 237$ & 1.5 & $5870 \pm 1660$ & 12.8 & $3.7 \pm 3.0$ & & \\
\hline & Fostamatinib $200 \mathrm{mg}$ & $395 \pm 136$ & 1.5 & $4430 \pm 1560$ & 14.3 & $2.6 \pm 1.1$ & & \\
\hline \multicolumn{9}{|c|}{ Japanese healthy subjects ( $n=12$ per dosage group) } \\
\hline & Fostamatinib $100 \mathrm{mg}$ & $477 \pm 237$ & 1 & $4640 \pm 1460$ & 13.3 & $3.0 \pm 1.0$ & & \\
\hline & Fostamatinib $200 \mathrm{mg}$ & $955 \pm 371$ & 1.25 & $8620 \pm 3270$ & 13.6 & $3.0 \pm 1.0$ & & \\
\hline \multicolumn{9}{|c|}{ Patients with renal disease ( $\mathrm{n}=8$ per group) } \\
\hline \multirow[t]{4}{*}{ Martin et al. 2015} & $\begin{array}{l}\text { Fostamatinib } 150 \mathrm{mg} \text { : } \\
\mathrm{CL}_{\mathrm{CR}} \geq 80 \mathrm{ml} / \mathrm{min}\end{array}$ & 690 & 2.5 & 7380 & 20.5 & & & [37] \\
\hline & $\mathrm{CL}_{\mathrm{CR}} \geq 30-<50 \mathrm{ml} / \mathrm{min}$ & 425 & 2.5 & 5790 & 23,8 & & & \\
\hline & ESRD post-dialysis & 407 & 2.3 & 5450 & 19.6 & & & \\
\hline & ESRD predialysis & 529 & 3.0 & 6810 & 22.1 & & & \\
\hline \multicolumn{9}{|c|}{ Patients with hepatic disease ( $n=8$ per group; Child-Pugh Class A, B and C) } \\
\hline & $\begin{array}{l}\text { Fostamatinib } 150 \mathrm{mg}: \\
\text { No hepatic impairment }\end{array}$ & 692 & 1.5 & 8970 & 19.4 & & & \\
\hline & Mild hepatic impairment & 615 & 2.5 & 6390 & 16.7 & & & \\
\hline & $\begin{array}{l}\text { Moderate hepatic } \\
\text { impairment }\end{array}$ & 602 & 1.8 & 6860 & 16.1 & & & \\
\hline & $\begin{array}{l}\text { Severe hepatic } \\
\text { impairment }\end{array}$ & 582 & 1.5 & 9490 & 19.2 & & & \\
\hline \multicolumn{9}{|c|}{ Patients with non-Hodgkin lymphoma } \\
\hline \multirow[t]{2}{*}{ Friedberg et al. 2010} & Fostamatinib $200 \mathrm{mg}$ & $668 \pm 258$ & & $1800 \pm 602$ & & & & [38] \\
\hline & Fostamatinib $250 \mathrm{mg}$ & $1020 \pm 781$ & & $2590 \pm 1900$ & & & & \\
\hline \multicolumn{9}{|c|}{ Patients with rheumatoid arthritis $(n=12)$} \\
\hline Baluom et al. 2011 & Fostamatinib $100 \mathrm{mg}$ & $397 \pm 177$ & $1.0 \pm 0.4$ & $3260 \pm 990$ & $14.5 \pm 4.3$ & & & [39] \\
\hline
\end{tabular}

In human healthy volunteers, absorption was rapid with peak R406 levels occurring between 1 and $2 \mathrm{~h}$ after administration of fostamatinib (R406 in one study) and having a median value of $1.5 \mathrm{~h}$ in all the studies included in Table 1. Absorption appeared to be slightly delayed in patients with renal insufficiency/failure $(2.3-3.0 \mathrm{~h})$ [37]. Dose proportional $\mathrm{C}_{\max }$ and $\mathrm{AUC}_{0-\infty}$ levels were observed at doses up to $400 \mathrm{mg}$ in healthy volunteers [35].

\section{Distribution}

R406 is highly bound to plasma proteins (98.3\% in human plasma) and distributes reversibly into blood cells [41]. The mean $( \pm S D)$ apparent volume of distribution $\left(V_{Z} / F\right)$ following single dose administration ranged between $306 \pm 95$ and $557 \pm 1661$ [Table 1] and at steady-state it was $256 \pm 921$ [41]. 


\section{Elimination}

Fostamatinib is metabolised in the gut by alkaline phosphatase to its main active metabolite R406. Subsequently, R406 is extensively metabolised, primarily through pathways of CYP450-mediated oxidation (by CYP3A4) and glucuronidation (by UDP glucuronosyltransferase [UGT]1A9). R406 is the predominant moiety in the systemic circulation, and there is minimal exposure to any of its metabolites [29].

Following absorption, R406 undergoes slow bi-phasic elimination with a terminal half-life $\left(\mathrm{t}_{1 / 2}\right)$; ranging between 12 and $21 \mathrm{~h}$ across the majority of groups, but between 20 and $24 \mathrm{~h}$ in patients with renal disease (Table 1). Approximately $20 \%$ of an administered dose is recovered in the urine, primarily as $\mathrm{N}$-glucuronide R406. About $80 \%$ of the dose was eliminated in the feces, mainly as R406 and 3,5-benzene diol R406 (with wide individual variation in the amounts of these metabolites recovered) [42].

\section{Food interactions}

Administration of fostamatinib with a high-calorie, high-fat meal (deriving approximately 150, 250 and 500-600 calories from protein, carbohydrate and fat, respectively) increased R 406 AUC by $23 \%$ and $C_{\max }$ by $15 \%$, indicating fostamatinib can be administered with or without food [41].

\section{Special populations}

Population analyses indicate that the pharmacokinetics of fostamatinib/R406 are not altered based on age, gender, race/ethnicity [41]. Nor are they altered in subjects with renal impairment (creatinine clearance [CLcr] $=30$ to $<50 \mathrm{ml} / \mathrm{min}$, estimated by Cockcroft Gault equation and end stage renal disease requiring dialysis), or hepatic impairment (Child-Pugh Class A, B and C) [37]. In line with the SmPC, fostamatinib should not be used in patients with severe hepatic impairment, and in patients with mild or moderate hepatic impairment, monitoring of liver function should be performed regularly during fostamatinib therapy [41].

\section{Clinical experience with fostamatinib in persistent/chronic immune thrombocytopenia}

In patients with persistent/chronic ITP the safety and efficacy of fostamatinib has been evaluated in individual cases in everyday clinical practice [43], in a Phase II open-label study [34] and in the FIT clinical trials programme comprising two double-blind, randomized, placebo-controlled, Phase III studies (FIT1 and FIT2; NCT02076399 and NCT02076412, respectively) [44,45], an on-going open-label extension study (FIT3; NCT02077192) [46-48] and two post hoc analyses [49,50] (Table 2). The FIT1 and FIT2 studies were of identical design and included a total of 150 adults with chronic ITP treated for 24 weeks. A total of 123 patients continued treatment with fostamatinib in the open-label on-going extension study (FIT3) which was the subject of an interim analysis after a median 6.7 (range 1-31) months [48].

\section{Case reports \& open-label study}

In a Phase II open-label pilot study, the clinical efficacy and tolerability/safety of escalating doses $(75-175 \mathrm{mg}$ twice daily) of fostamatinib was evaluated in 16 adult patients with refractory chronic ITP [34]. All patients were required to have failed at least 2 typical treatments prior to entry (including corticosteroids, $100 \%$; IVIg, 94\%; rituximab, 88\%; splenectomy, 69\%; anti-D, 56\%; danazol, 50\%) and have at least 3 separate platelet counts of $<30 \times 10^{9} / 1$ over a 3-month period. Treatment was initiated with fostamatinib 75-150 mg twice daily and this could be increased every 2 weeks, by $25 \mathrm{mg}$ twice daily, up to a maximum of $175 \mathrm{mg}$ twice daily. The dosage was escalated until a persistent response was achieved, the maximum dosage was reached or toxicity occurred. Response assessment were made weekly for the first 7 weeks and then every 1-4 weeks depending on the patient's response. The key findings are outlined in Table 2. Eight of the 16 patients (50\%) achieved a sustained response with a reduced need for IVIg and tapering of steroid therapy; four patients had transient nonsustained responses; and four patients did not respond to treatment.

Real-world experience in treating patients with chronic ITP at the Boston Medical Center Health System were presented at the 2019 American Society of Hematology (ASH) meeting [43]. Four patients were retrospectively identified and all were refractory to, or could not tolerate, previous treatment with corticosteroids, IVIg and rituximab, and two also failed treatment with the thrombopoietin agonists romiplostim and eltrombopag. Fostamatinib was started at a dosage of $100 \mathrm{mg}$ orally twice daily and titrated up to $150 \mathrm{mg}$ twice daily if the platelet count was $<50 \times 10^{9} / 1$. The duration of follow-up was 2 to 9 months. After 4 weeks, three patients had platelet counts 
Table 2. Clinical studies/trials with oral fostamatinib in patients with primary persistent/chronic immune

\section{thrombocytopenia.}

\begin{tabular}{|c|c|c|c|c|c|}
\hline $\begin{array}{l}\text { Study design [no. } \\
\text { pts] }\end{array}$ & $\begin{array}{l}\text { Fostamatinib dosage } \\
\text { (oral) [duration of } \mathrm{Rx} \text { ] }\end{array}$ & Response end point & Main efficacy findings & Reference & Ref. \\
\hline \multicolumn{6}{|c|}{ Case reports and open-label study } \\
\hline $\begin{array}{l}\text { Open-label, Phase II } \\
\text { study }[n=16]\end{array}$ & $\begin{array}{l}75 \mathrm{mg} \text { bid escalated at } \\
\text { doses of } 25 \text { bid up to } \\
175 \mathrm{mg} \text { bid [3-53 w] }\end{array}$ & $\begin{array}{l}\uparrow \text { in platelet count by } \\
>20 \times 10^{9} / \text { I from baseline } \\
\text { to } \geq 30 \times 10^{9} / \text { I with no } \\
\text { rescue treatment }\end{array}$ & $\begin{array}{l}\text { Efficacy: } 12 / 16 \text { pts }(75 \%) \text { achieved a positive response } \\
\text { which was sustained in eight pts. Median platelet } \\
\text { count peaked at } 105 \times 10^{9} / \text { I from a baseline of } \\
16 \times 10^{9} / \text { I. A total of eight pts had a persistent } \\
\text { response (platelet count }>50 \times 10^{9} / \text { for a median of } \\
95 \% \text { study visits and a median peak platelet count of } \\
\left.188 \times 10^{9} / \mathrm{l}\right) . \text { Four pts had a nonsustained transient } \\
\text { response and } 4 \text { pts did not respond to treatment } \\
\text { Safety: Overall, the tolerability of fostamatinib was } \\
\text { good, but three pts discontinued treatment because } \\
\text { of toxicity (one case each of: deep vein thrombosis } \\
\text { (unrelated); vomiting and diarrhea; and elevated } \\
\text { transaminase levels). Other, mostly mild to moderate } \\
\text { AEs probably related to fostamatinib included GI } \\
\text { events, elevated SBP, headache and weight gain }\end{array}$ & $\begin{array}{l}\text { Podolanczuk et al. } \\
2009\end{array}$ & [34] \\
\hline Individual cases & $\begin{array}{l}100 \mathrm{mg} \text { bid increased to } \\
150 \mathrm{mg} \text { bid if platelet } \\
\text { count was }<50 \times 10^{9} / \mathrm{I} \\
{[2-9 \mathrm{~m}]}\end{array}$ & $\begin{array}{l}\text { Fostamatinib suitability in } \\
4 \text { pts at an Academic } \\
\text { Medical Center refractory } \\
\text { to previous therapy }\end{array}$ & $\begin{array}{l}\text { Efficacy: Three pts received fostamatinib because of } \\
\text { side effects or inconvenience with ROM. } \\
\text { After } 4 \mathrm{w} \text {, three pts had a platelet count of } \\
>50 \times 10^{9} / \mathrm{l} \text { and in } 1 \mathrm{pt} \text { it was }<30 \times 10^{9} / \mathrm{l} \text {. For two } \\
\text { pts who have been on therapy for } 7-8 \mathrm{~m} \text { platelet } \\
\text { count s were }>100 \times 10^{9} / \mathrm{I} \text {. Two pts discontinued } \\
\text { fostamatinib; } 1 \text { due to an inadequate response and } 1 \\
\text { because an adverse eventSafety: Two pts developed } \\
\text { diarrhea ( } 1 \text { discontinued treatment) and one pt } \\
\text { experienced elevated BP }\end{array}$ & Hughes et al. 2019 & {$[4,43]$} \\
\hline \multicolumn{6}{|c|}{ FIT $(1,2,3)$ clinical trials programme } \\
\hline $\begin{array}{l}\text { MC, R (2:1), D-B, PC, } \\
\text { Phase III study } \\
{[n=76]}\end{array}$ & $\begin{array}{l}100 \mathrm{mg} \text { bid with an } \\
\text { increase to } 150 \mathrm{mg} \text { bid } \\
\text { allowed depending on } \\
\text { platelet count and } \\
\text { tolerability }(n=51) \text { or } \\
\text { placebo }(n=25)[24 \mathrm{w}]\end{array}$ & $\begin{array}{l}\text { Overall response (platelet } \\
\text { count } \geq 50 \times 10^{9} / I \\
\text { between weeks } 1 \text { and } 12 \text { ) } \\
\text { Primary end point: Stable } \\
\text { platelet response by week } \\
24 \text { ( } \geq 50 \times 10^{9} / I \text { on at least } \\
4 \text { of the last sox visits } \\
\text { between weeks } 14 \text { and } 24)\end{array}$ & $\begin{array}{l}\text { Efficacy: Overall response: fostamatinib } 37 \% \text { vs PL } 8 \% \\
(p<0.01) \text { Stable platelet response: fostamatinib } 18 \% \\
\text { vs PL } 0 \%(p<0.05)\end{array}$ & FIT1 NCT02076399 & [44] \\
\hline $\begin{array}{l}\text { MC, R (2:1), D-B, PC, } \\
\text { Phase III study }\end{array}$ & $\begin{array}{l}100 \mathrm{mg} \text { bid with an } \\
\text { increase to } 150 \mathrm{mg} \text { bid } \\
\text { allowed depending on } \\
\text { platelet count and } \\
\text { tolerability }(n=50) \text { or } \\
\text { placebo }(n=24)[24 \mathrm{w}]\end{array}$ & & $\begin{array}{l}\text { Efficacy: Overall response: fostamatinib } 48 \% \text { vs PL } \\
21 \%(p<0.05) \text { Stable platelet response: fostamatinib } \\
18 \% \text { vs PL } 4 \% \text { (NS) }\end{array}$ & FIT2 NCT02076412 & {$[45,74]$} \\
\hline $\begin{array}{l}\text { MC, R (2:1), D-B, PC, } \\
\text { Phase III studies } \\
\text { pooled [ } n=150]\end{array}$ & $\begin{array}{l}100 \mathrm{mg} \text { bid with an } \\
\text { increase to } 150 \mathrm{mg} \text { bid } \\
\text { allowed depending on } \\
\text { platelet count and } \\
\text { tolerability }(n=101) \text { or } \\
\text { placebo }(n=49)[24 \mathrm{w}]\end{array}$ & As above & 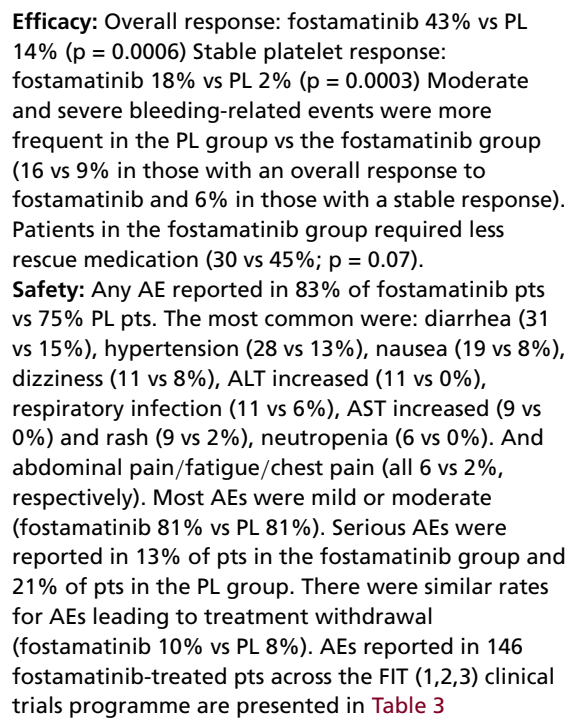 & $\begin{array}{l}\text { Pooled results FIT1 } \\
\text { and FIT2 Bussel } \\
\text { et al. 2018, } 2019 .\end{array}$ & $\begin{array}{r}{[44,45} \\
47,48]\end{array}$ \\
\hline
\end{tabular}




\begin{tabular}{|c|c|c|c|c|c|}
\hline $\begin{array}{l}\text { Study design [no. } \\
\text { pts] }\end{array}$ & $\begin{array}{l}\text { Fostamatinib dosage } \\
\text { (oral) [duration of } \mathbf{R x} \text { ] }\end{array}$ & Response end point & Main efficacy findings & Reference & Ref. \\
\hline $\begin{array}{l}\text { Open-label } \\
\text { extension study } \\
\text { from FIT1 and FIT2 } \\
{[n=123]}\end{array}$ & $\begin{array}{l}100 \mathrm{mg} \text { bid with an } \\
\text { increase to } 150 \mathrm{mg} \text { bid } \\
\text { allowed depending on } \\
\text { platelet count and } \\
\text { tolerability [1.5-41.3 m] }\end{array}$ & $\begin{array}{l}\text { Achievement and } \\
\text { maintenance of a stable } \\
\text { platelet count } \geq 50 \times 10^{9} / \mathrm{l} \\
\text { for } 12 \mathrm{~m} \text {. }\end{array}$ & $\begin{array}{l}\text { Efficacy: Median duration of fostamatinib treatment } \\
\text { was } 8.9 \text { m and median compliance was } 98 \% \text {. } 42 \text { of } \\
123 \text { pts were continuing fostamatinib treatment. Of } \\
27 \text { pts with a stable response, } 21(78 \%) \text { had } \\
\text { maintained the response for } 1 \text { year and } 15(56 \%) \text { for } \\
2 \text { years. A total of } 32 \text { pts had data after } 2 \text { years and } \\
\text { the median platelet count was } 81 \times 10^{9} / \text {. An overall } \\
\text { platelet response was achieved by } 57 / 123(46 \%) \text { of } \\
\text { patients } \\
\text { Safety: AEs were reported by } 95(77 \%) \text { pts and were } \\
\text { mild/moderate in } 92(75 \%) \text { of cases. The most } \\
\text { common AEs were diarrhea and hypertension which } \\
\text { were manageable with appropriate treatment, dose } \\
\text { modification or treatment discontinuation ( } 5 \text { pts). } \\
\text { SAEs were reported by } 28 \text { pts ( } 23 \text { unrelated to } \\
\text { fostamatinib) and these included } 11 \text { with } \\
\text { bleeding-related events, TCP in six pts, epistaxis in } \\
\text { three, sepsis in two and increased liver enzymes in } \\
\text { two. In this long-term study no new safety signals } \\
\text { were observed }\end{array}$ & $\begin{array}{l}\text { FIT3 Bussel et al. } \\
\text { 2019, Duliege et al. } \\
2018\end{array}$ & {$[46,48,49]$} \\
\hline $\begin{array}{l}\text { Post hoc analysis } \\
\text { from FIT1 and } 2 \text { to } \\
\text { assess second-line } \\
\text { [n=32] and early } \\
\text { use [n }=29]\end{array}$ & $\begin{array}{l}\text { Dosage as per FIT1 and } 2 \text {. } \\
\text { Only pts who had failed } \\
\text { treatment with } \\
\text { steroids } \pm \text { immunoglobu- } \\
\text { lins and no other therapies } \\
\text { (i.e. second-line therapy, } \\
\text { and those treated early in } \\
\text { the disease }\end{array}$ & $\begin{array}{l}\text { Platelet responses in pts } \\
\text { receiving fostamatinib } \\
\text { early ( }<2 \text { years) and as } \\
\text { second-line therapy }\end{array}$ & $\begin{array}{l}\text { A total of } 32 \text { of } 145 \text { pts received fostamatinib as } \\
\text { second-line therapy and } 25(78 \%) \text { had an overall } \\
\text { platelet response (platelet count } \geq 50 \times 10^{9} / \mathrm{l} \text { ) which } \\
\text { compares very favorably with the } 47 \% \text { response rate } \\
\text { in the } 113 \text { pts who received it as } \geq 3^{\text {rd }} \text { line therapy. In } \\
\text { the subgroup of } 29 \text { pts who received fostamatinib } \\
\text { early ( }<2 \text { years), } 9 \text { of } 10 \text { pts }(90 \%) \text { who received the } \\
\text { drug }<1 \text { year and } 11 \text { of } 19(57 \%) \text { who received it } \\
\text { between } 1-<2 \text { years responded. These compare } \\
\text { favorably with the response rate of } 50 \% \text { in pts with } \\
\text { ITP for } 2-53 \text { years. AEs were consistent with the main } \\
\text { study }\end{array}$ & Boccia et al. 2020 & [51] \\
\hline
\end{tabular}

AE: Adverse event; ALT: Alanine aminotransferase; AST: Aspartate aminotransferase; RTI: Respiratory tract infection; bid: Twice daily; D-B: Double-blind; m: Months; MC: Multicentre; PC: Placebo-controlled; W: Week; PL: Placebo; R: Randomized; ROM: Romiplostim; Rx: Treatment; SAE: Serious AE; SBP: Systolic blood pressure; TCP: Thrombocytopenia.

$>50 \times 10^{9} / 1$ and in one patient it was $<30 \times 10^{9} / 1$. For two pts who have been on therapy for $7-8$ months, platelet counts were $>100 \times 10^{9} / 1$ (Table 2$)$.

\section{FIT $(1,2,3)$ clinical trials programme}

The efficacy of fostamatinib in ITP has been confirmed in 2 identically designed double-blind, randomized, placebocontrolled, Phase III studies [44,45], an open-label, on-going extension study [46] and in a pooled analysis from these studies [47-49]. The FIT1 (patients from N. America, Australia and Europe) and FIT2 (Europe only) studies were conducted in 150 adults with chronic ITP over 24 weeks, and the FIT3 study in 123 of these patients treated for between an additional 1.5 and 41.3 months (Table 2). The patients were refractory to previous ITP therapy which included three unique prior regimens including corticosteroids, splenectomy, TPO-RAs and/or rituximab (93\% had received corticosteroids, 51\% IVIg or IV Anti-D, 47\% TPO-RAs, 34\% had received rituximab and 34\% had undergone splenectomy). At baseline, the median duration of disease was 8.5 years (and about $75 \%$ had a $\geq 3$-year history of ITP), and all patients had at least three platelet counts $<30 \times 10^{9} / 1$ including 2 measurements within the preceding 3 months. These demographic data highlight that this was a difficult-to-treat ITP cohort. Fostamatinib was administered orally at a starting dose of $100 \mathrm{mg}$ twice daily which could be titrated to $150 \mathrm{mg}$ twice daily (depending on platelet count and tolerability) after week 4 . By the end of the study period, $88 \%$ of patients were receiving $150 \mathrm{mg}$ twice daily.

Results for the primary end point, a stable response which was defined as a platelet count of $\geq 50 \times 10^{9} / 1$ on at least four of six visits during weeks 14 through 24, are presented in Table 2. Combined results from the FIT1 and FIT2 studies demonstrated a stable response rate of $18 \%$ with fostamatinib versus $2 \%$ with placebo $(\mathrm{p}=0.0003)$, and an overall response rate (defined as a platelet count of $\geq 50 \times 10^{9} / 1$ during weeks 1 to 12 and a post hoc analysis) of $43 \%$ with fostamatinib versus $14 \%$ with placebo $(\mathrm{p}=0.0006)$. In patients with more severe ITP at baseline as defined by a platelet count of $<15 \times 10^{9} / 1$, an increase to $30 \times 10^{9} / 1$ at weeks 12 and 24 was achieved 


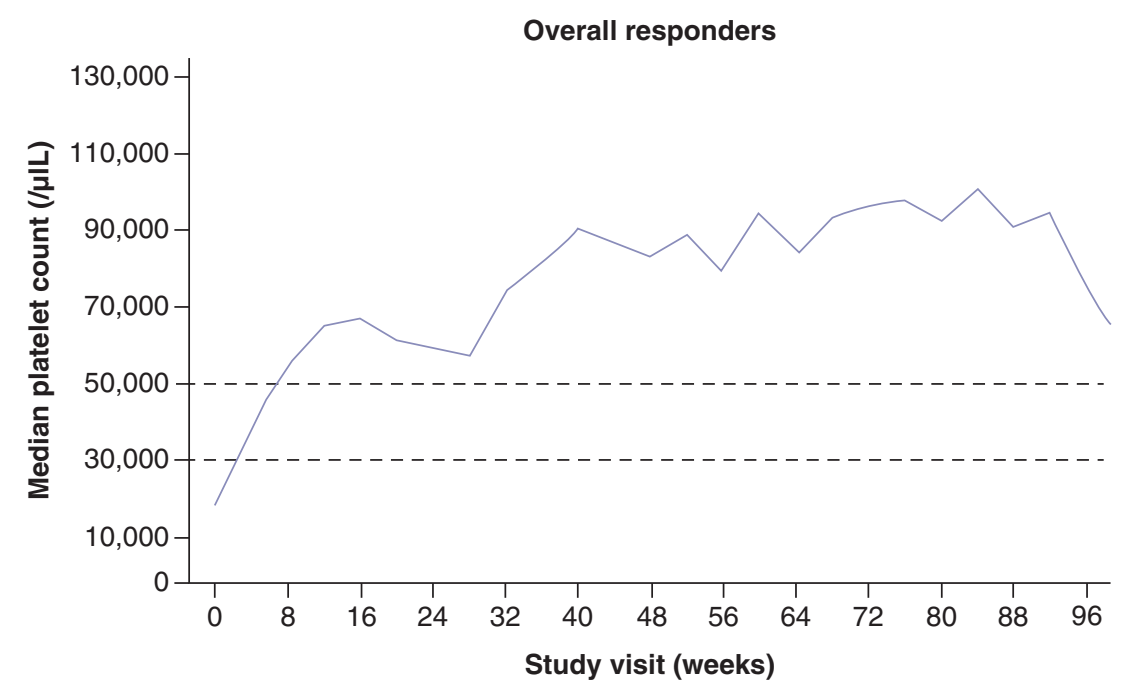

Overall responder

53636256534746474037403434362830292622211820141111

Figure 4. Median platelet counts in overall and stable responders over time.

Republished with permission of John Wiley \& Sons [48]; permission conveyed through Copyright Clearance Center, Inc.

by 21 and $15 \%$ of patients in the fostamatinib group versus 5 and $0 \%$ of the placebo group. Median platelet counts from baseline levels over 24 weeks were $95 \times 10^{9} / 1$ in stable responders, $49 \times 10^{9} / 1$ in overall responders, $14 \times 10^{9} / 1$ in nonresponders and $18 \times 10^{9} / 1$ with placebo [47]. Platelet responses to fostamatinib were relatively rapid, and both overall and stable responders achieved an initial platelet threshold of $\geq 50 \times 10^{9} / 1$ after a median of approximately 15 days. However, in some individuals a slower but steady response was observed and the platelet count that exceeded $50 \times 10^{9} / 1$ during weeks 2 to 12 or after the initial 12 -week treatment period. A positive response to fostamatinib was demonstrated across all subgroups; age, gender; prior therapy; baseline platelet count and duration of ITP.

In the Phase III clinical trials and open-label extension trial a total of 146 patients were treated with fostamatinib, and 64 patients (44\%) achieved an overall response. This included 43 of 101 (43\%) initially treated with fostamatinib, and 21 of 44 (48\%) patients who transitioned to fostamatinib after initially receiving placebo. The overall response to fostamatinib was maintained during treatment and median platelet counts remained $\geq 50 \times 10^{9} / 1$ at all visits; with a median post-baseline platelet count of $63 \times 10^{9} / 1$ (range 15 to $\left.277 \times 10^{9} / 1\right)$ (Figure 4) [48]. The majority of patients maintained their response to fostamatinib for a median duration $>28$ months (range $<1$ to $>28$ months). In patients who had an insufficient response to TPO-RAs $(n=69), 24(35 \%)$ had an overall response to fostamatinib and 14 of these maintained platelet counts consistently above $30 \times 10^{9} / 1$ [48].

In the FIT1 and FIT2 randomized studies, 17 patients (17\%) achieved the primary end point (a stable response to fostamatinib), and 10 of 44 (23\%) patients who switched from the placebo group also achieved this end point with fostamatinib in the open-label extension study. Thus, a stable response was recorded in $18 \%$ of patients (27 of 146) in the fostamatinib-treated population [50]. The response to fostamatinib was durable with 18 of 27 (67\%) patients maintaining a stable response for $\geq 1$ year. An additional seven stable responders (26\%) remained on fostamatinib for $>1$-year as a result of continued clinical benefit (this was despite having $\geq 1$ platelet count drop $<50 \times 10^{9} / \mathrm{l}$ ), and five of these patients regained their response. The other two patients with a stable response had not reached 12 months of therapy as of the data cut-off date. Overall, after 12 months of treatment, 93\% of stable responders maintained their clinical response or continued to derive benefit on fostamatinib treatment. The median duration of the first stable response was not reached in this study and the authors estimated that it was $>28$ months. These patients continue to be monitored in the on-going FIT3 study [46-50].

Post hoc analyses from the FIT1 and FIT2 trials were undertaken to assess second-line and early use of fostamatinib in patients with ITP [51]. Only patients who had failed treatment with steroids \pm immunoglobulins and no other therapies $(\mathrm{n}=32)$, and those treated early in the course of the disease ( $<2$ years) were included in these analyses. When used as second-line therapy $25(78 \%)$ fostamatinib-treated patients had an overall response (platelet count $\geq 50 \times 10^{9} / 1$ ), which compares very favorably with the $48 \%$ response rate in the 113 pts who received it as $\geq 3^{\text {rd }}$ 
line therapy. In the subgroup of 29 patients with early stage disease, nine of ten patients (90\%) with persistent ITP (disease duration $<1$ year) and 11 of $19(58 \%)$ with ITP for between 1 and $<2$ years responded to fostamatinib. These rates compare favorably with the response rate of $51 \%$ in patients with ITP for $2-53$ years. These results suggest that higher response rates may be achieved when fostamatinib is used as second-line treatment for ITP and in patients with early ( $<2$ years) disease, compared with later lines of therapy and more chronic disease ( $>2$ years) [51].

\section{Bleeding-related end points \& need for rescue medication}

In patients treated with fostamatinib, moderate to severe bleeding-related events were reported by four of 43 (9\%) overall responders and six of $58(10 \%)$ non-responders, versus eight of $49(16 \%)$ patients on placebo [47]. Serious bleeding-related events did not occur in any of the 43 overall responders to fostamatinib compared with 4 of 58 (7\%) of non-responders and five of 49 (10\%) of placebo-treated patients. Rescue medication was used by $16 \%$ of responders and $34 \%$ of nonresponders to fostamatinib, compared with $45 \%$ of patients receiving placebo. In stable responders, three of 18 (17\%) used rescue medication, and only during the first week of treatment, whereas nonresponders and placebo patients used rescue medication throughout the study (up to week 24) [47]. Types of rescue medication included IVIg, corticosteroids, and platelet transfusion, as recommended by clinical guidelines.

In population-based cohort studies, ITP was associated with thromboembolic events at a rate estimated to be twofold higher than the general population [52]. Analysis of data from the FIT 1, 2, 3 studies identified a single transient ischemic attack $(0.7 \%)$ in patients treated with fostamatinib. This involved a patient with pre-existing atherosclerosis and the case resolved spontaneously [53]. This low incidence of thromboembolism with fostamatinib may relate to its mechanism of action (Syk inhibition) and deserves further evaluation.

\section{Tolerability \& safety}

In patients with ITP, fostamatinib has generally been well tolerated in Phase III studies. Approximately, $10 \%$ of fostamatinib-treated patients discontinued treatment compared with $8 \%$ of patients receiving placebo [47]. The most commonly reported AEs for fostamatinib are consistent with those previously reported for Syk inhibitors, including gastrointestinal disorders, hypertension, and transaminase elevation (Table 3) [48]. The majority of AEs were mild/moderate in severity and were manageable with appropriate monitoring and standard therapeutic approaches, including appropriate treatment of the $\mathrm{AE}$, dose reduction/treatment interruption, and infrequently discontinuation of fostamatinib [50]. In total, $31 \%$ of patients treated with fostamatinib versus $17 \%$ on placebo required modification of their treatment: interruption (18 vs 10\%), dose reduction ( 9 vs $2 \%$ ), or withdrawal (10 vs $8 \%$ ). Serious AEs (SAEs) were reported in $13 \%$ of patients in the fostamatinib group and $21 \%$ of patients in the placebo group; 4 vs $2 \%$, respectively, were considered to be drug-related $[47,48]$. There were two deaths, one in the placebo group (from probable sepsis 19 days after discontinuing the study) and one in the fostamatinib group (plasma cell myeloma which led to withdrawal from the study and death 71 days later), but causality was not ascribed. Only 3 SAEs were reported in more than one patient: epistaxis ( $2 \%$ fostamatinib vs $2 \%$ placebo), menorrhagia ( 0 vs $4 \%$ ) and thrombocytopenia ( 1 vs $4 \%$ ).

In an interim report of the long-term extension study that is ongoing, AEs were reported by 95 (77\%) patients and were mild to moderate in $92(75 \%)$ of cases [49]. The most common AEs were diarrhea and hypertension which were manageable with appropriate treatment, dose modification/interruption, or treatment discontinuation (five patients). SAEs were reported by 28 pts ( 23 unrelated to fostamatinib) and these included 11 bleeding-related events (thrombocytopenia $n=6$, epistaxis $n=3$ and sepsis $n=2$ ). In this long-term study no new safety signals were observed and the overall safety profile of fostamatinib in ITP clinical trials was consistent with its use in other indications such as rheumatoid arthritis $[14,50]$.

\section{Conclusions / place in therapy (meeting unmet needs)}

It is widely acknowledged that over the last decade management of ITP has markedly improved but it is not optimal, and a key reason for this is the heterogeneity of the disorder with regards to its underlying pathophysiology, variable presentation and the differing individual responses to treatment. This highlights the need for a personalized approach to treatment with management tailored to the needs of the individual, taking into consideration factors such as age, extent of bleeding, comorbidities predisposing to bleeding, bleeding risks with necessary concomitant medications, complications associated with the treatments being considered, possible adverse effects, lifestyle considerations, patient concerns/worries and accessibility to care [12]. These factors were taken into consideration by an expert panel that produced an updated International Consensus Report based on clinical best evidence available up to July 
Table 3. The most common adverse events $(\%)$ reported during fostamatinib treatment in the FIT $(1,2,3)$ clinical trials programme $(n=146)$.

\begin{tabular}{|c|c|c|c|c|}
\hline Type of AE & Mild AEs & Moderate AEs & Severe AEs & Total AEs \\
\hline Total AEs & 21 & 41 & 23 & 86 \\
\hline Serious AEs & \multicolumn{4}{|c|}{$38(26 \%)$ pts had serious AEs which were judged to be related to drug treatment } \\
\hline Diarrhea & 18 & 16 & 1 & 35 \\
\hline Hypertension & 10 & 10 & 1 & 21 \\
\hline Nausea & 17 & 2 & 0 & 19 \\
\hline Epistaxis & 11 & 6 & 0 & 17 \\
\hline Petechiae & 10 & 4 & 1 & 15 \\
\hline Headache & 9 & 4 & 0 & 13 \\
\hline Dizziness & 9 & 1 & 1 & 11 \\
\hline Upper RTI & 7 & 3 & 0 & 10 \\
\hline Elevated ALT & 6 & 4 & 0 & 10 \\
\hline Fatigue & 8 & 1 & 0 & 9 \\
\hline Vomiting & 8 & 0 & 0 & 8 \\
\hline Contusion & 6 & 1 & 1 & 8 \\
\hline Elevated AST & 4 & 3 & 0 & 7 \\
\hline Abdominal pain & 3 & 2 & 0 & 6 \\
\hline Nasopharyngitis & 6 & 0 & 0 & 6 \\
\hline Cough & 4 & 1 & 0 & 6 \\
\hline Dyspnea & 3 & 1 & 1 & 6 \\
\hline Rash & 6 & 0 & 0 & 6 \\
\hline Chest pain (non-cardiac) & 3 & 2 & 1 & 6 \\
\hline Neutropenia & 2 & 3 & 1 & 6 \\
\hline Thrombocytopenia & 0 & 1 & 5 & 6 \\
\hline
\end{tabular}

2018. For adult patients requiring initial treatment for newly-diagnosed ITP they recommended corticosteroids along with the immunoglobulins IVIg and IV-anti-D, and as subsequent therapy the recommended choices (with the most robust evidence) were TPO-RAs, fostamatinib and rituximab [12]. During this period there has been a move away from splenectomy, which is now recommended upon failure of medical therapies [12]. Treatment is also recommended on the basis of clinical need rather than the platelet count alone, or the artificial definition into newly presented, persistent or chronic categories.

Fostamatinib as a prodrug, and R406 as its active moiety, represent a novel treatment approach which can be orally administered and requires minimal titration; reducing both clinical time and the need for professional healthcare support. It was shown to produce a rapid, durable response among patients with long-standing ITP who were considered difficult to treat having previously received rituximab, and/or TPO-RAs or had undergone splenectomy [48]. Subgroup analyses illustrate good overall responses independent of duration of ITP, baseline platelet count, previous TPO-RA or rituximab therapy, and prior splenectomy. These results demonstrate that fostamatinib is able to improve platelet numbers among diverse types of patients, including those with and without multiple exposures to prior ITP treatments, and those with longer and shorter durations of ITP [47]. The findings from the FIT $(1,2,3)$ clinical trials programme resulted in the approval of fostamatinib by the US FDA in April 2018 and the EMA in Europe in January 2020. Patients who responded to fostamatinib demonstrated good control of hemostasis.

Overall, fostamatinib was well tolerated, and adverse effects were generally predictable for a Syk inhibitor (including gastrointestinal effects such as diarrhea, hypertension and liver transaminase elevations) and could be managed with dose reduction/interruption, appropriate treatment or infrequently by discontinuation. Wider usage in everyday clinical practice, following its relatively recent approvals in the US and Europe, will provide a more grounded and comprehensive understanding of the efficacy and safety profile of fostamatinib in ITP and will help us define those patients most likely to benefit from this novel new therapeutic approach. 
In the Phase III clinical trials, a stable platelet response (platelet count of $>50 \times 10^{9} / 1$ ) was significantly higher for fostamatinib versus placebo ( $18 \mathrm{vs} 2 \% ; \mathrm{p}=0.0003$ ). The median platelet count in fostamatinib stable responders $\left(95 \times 10^{9} / \mathrm{l}\right)$ and overall responders $\left(49 \times 10^{9} / \mathrm{l}\right)$ was markedly higher than that for placebo $\left(18 \times 10^{9} / \mathrm{l}\right)$. A positive response to fostamatinib was demonstrated across all subgroups for example, age, gender, prior therapy baseline platelet count and duration of ITP.

Across the 2 Phase III clinical trials and open-label extension study, 64 of 146 patients (44\%) achieved an overall response. Overall, $93 \%$ of patients who achieved a stable response continued to respond and/or derive clinical benefit after 12 months of treatment.

The safety profile of fostamatinib in clinical trials involving patients with ITP is consistent with its safety profile in other indications, with most common AEs including gastrointestinal-related reactions (diarrhea, nausea and vomiting) and elevated blood pressure; most AEs have been mild to moderate, self-limited and did not lead to treatment discontinuation.

Compared with placebo, elevated liver transaminase levels and hypertension events were recorded in some fostamatinib-treated patients, but these could generally be managed with appropriate treatment or dose reductions.

\section{Conclusion}

Preclinical and Phase II and III clinical studies have shown fostamatinib to be a promising new approach to ITP that may be effective in heavily pretreated patients.

\section{Executive Summary}

\section{Overview of immune thrombocytopenia}

- Primary immune thrombocytopenia (ITP) is a heterogeneous autoimmune bleeding disease resulting in autoantibody-mediated premature destruction/clearance of platelets and reduced platelet production by megakaryocytes.

- Disruption of T- and B-cell tolerance mechanisms, as a result of somatic mutations, lead to the development of platelet reactive autoantibodies that contribute to the pathogenesis of ITP.

- Most patients with ITP have a skewed Th1/Th2 ratio that favors the survival of autoreactive T-cell clones that produce anti-GPIIbIIla and Ib/IX antibodies; these attach to the surface of platelets which are, in turn, cleared by splenic macrophages through Syk-dependent phagocytosis.

Unmet medical need

- Despite the availability of several different therapeutic approaches, with drugs having different mechanisms of action. ITP is able to persist for a number of years.

- Corticosteroids (with or without IVIg and anti-D) are recommended as first-line therapy in treatment guidelines while second-line choices include drugs such as the TPO-RAs, fostamatinib and rituximab. It is generally recommended to wait $\geq 12$ to 24 months before considering splenectomy, which is viewed as 'subsequent therapy: surgical.'

Overview of fostamatinib disodium

- Fostamatinib disodium is a first-in-class selective orally active spleen tyrosine kinase inhibitor indicated for the treatment of ITP by protecting platelets from destruction by inhibiting FCR-triggered cytoskeletal rearrangements needed for phagocytosis.

- Fostamatinib has been studied clinically in studies involving patients with autoimmune hemolytic anemia, ITP, lymphoma, nephropathy and rheumatoid arthritis; as well as in preclinical models of autoimmune disease.

Preclinical studies of fostamatinib in ITP

- Fostamatinib is a highly bioavailable prodrug that is metabolized to tamatinib (R406), its active metabolite, in the presence of alkaline phosphatase or human intestinal microsomes in vitro.

- R406 was a selective and potent inhibitor of Syk in both in vitro and cell-based assays. It was found to bind to the catalytic domain of Syk and acted as a competitive inhibitor of ATP.

- The onset/progression of autoimmune and inflammatory diseases were inhibited or delayed by fostamatinib in several animal models.

- Fostamatinib is rapidly absorbed, and its active metabolite (R406) has a terminal half-life ranging from 12 to $21 \mathrm{~h}$, and the majority of a dose $(\sim 80 \%)$ is eliminated in the feces.

Clinical studies of fostamatinib in ITP

- In patients with persistent/chronic ITP, fostamatinib has been evaluated in one Phase II trial $(n=16)$, two Phase III clinical trials $(n=75$ each), and an open-label extension study involving 124 patients previously enrolled in the Phase III studies.

- In the Phase II study, $50 \%$ of patients had sustained responses to fostamatinib and $25 \%$ had transient responses. 
Financial \& competing interests disclosure

A Newland has acted as a consultant for Amgen, Angle, Argenx, Grifols, GSK, Novartis and UCB Biosciences; he has also participated in advisory boards and/or as a speaker at medical education events sponsored by Amgen, Argenx, Grifols, GSK, Novartis and Roche; and, finally, he has received research support from Amgen, BMS, GSK, Novartis and Octapharma. V McDonald has received research support from Baxter and advisory fees from Alexion. The authors have no other relevant affiliations or financial involvement with any organization or entity with a financial interest in or financial conflict with the subject matter or materials discussed in the manuscript apart from those disclosed.

Medical writing support in line with Good Publishing Practice-3 guidelines was provided by Steve Clissold PhD on behalf of Content Ed Net, and was funded by Grifols S.A. (Barcelona, Spain).

\section{Open access}

This work is licensed under the Attribution-NonCommercial-NoDerivatives 4.0 Unported License. To view a copy of this license, visit http://creativecommons.org/licenses/by-nc-nd/4.0/

\section{References}

Papers of special note have been highlighted as: $\bullet$ of interest; $\bullet \bullet$ of considerable interest

1. Rodeghiero F, Stasi R, Gernsheimer T et al. Standardization of terminology, definitions and outcome criteria in immune thrombocytopenic purpura of adults and children: report from an international working group. Blood 113(11), 2386-2393 (2009).

- Recommendations for standard terminology and definitions for primary immune thrombocytopenic purpura (ITP) and its different phases and criteria for the grading of severity, and clinically meaningful outcomes and response.

2. Zufferey A, Kapur R, Semple J. Pathogenesis and therapeutic mechanisms in immune thrombocytopenia (ITP). J. Clin. Med. 6(2), 1-21 (2017).

3. Cooper N, Ghanima W. Immune thrombocytopenia. N. Engl. J. Med. 381(10), 945-955 (2019).

4. Cohen YC, Djulbegovic B, Shamai-Lubovitz O, Mozes B. The bleeding risk and natural history of idiopathic thrombocytopenic purpura in patients with persistent low platelet counts. Arch. Intern. Med. 160(11), 1630-1638 (2000).

5. Kistangari G, McCrae KR. Immune thrombocytopenia. Hematol. Oncol. Clin. North Am. 27(3), 497-520 (2013).

6. Segal JB, Powe NR. Prevalence of immune thrombocytopenia: analyses of administrative data. J. Throm. Haemost. 4, $2377-2383$ (2006).

7. Terrell DR, Beebe LA, Neas BR, Vesely SK, Segal JB, George JN. Prevalence of primary immune thrombocytopenia in Oklahoma. Am. J. Hematol. 87(9), 843-847 (2012).

8. Feudjo-Tepie MA, Robinson NJ, Bennett D. Prevalence of diagnosed chronic immune thrombocytopenic purpura in the US: analysis of a large US claim database: a rebuttal. J. Thromb. Haemost. 6(4), 711-713 (2008).

9. Terrell DR, Beebe LA, Vesely SK, Neas BR, Segal JB, George JN. The incidence of immune thrombocytopenic purpura in children and adults: A critical review of published reports. Am. J. Hematol. 85(3), 174-180 (2010).

10. Fogarty PF, Segal JB. The epidemiology of immune thrombocytopenic purpura. Curr. Opin. Hematol. 14(5), 515-519 (2007).

11. Brown TM, Horblyuk RV, Grotzinger KM, Matzdorff AC, Pashos CL. Patient-reported treatment burden of chronic immune thrombocytopenia therapies. BMC Blood Disord. 12(2), Published 2012 Mar 22. doi:10.1186/1471-2326-12-2 (2012).

12. Provan D, Arnold DM, Bussel JB et al. Updated international consensus report on the investigation and management of primary immune thrombocytopenia. Blood Advances 3(22), 3780-3817 (2019).

- International consensus guidelines for the diagnosis and management of primary ITP, frequently referenced to aid clinicians in decision making.

13. Crowley MT, Costello PS, Fitzer-Attas CJ et al. A critical role for Syk in signal transduction and phagocytosis mediated by Fc $\gamma$ receptors on macrophages. J. Exp. Med. 186(7), 1027-1039 (1997).

14. Newland A, Lee EJ, McDonald V, Bussel JB. Fostamatinib for persistent/chronic adult immune thrombocytopenia. Immunotherapy. 10(1), 9-25 (2018).

15. Cines DB, Bussel JB, Liebman HA et al. The ITP syndrome: pathogenic and clinical diversity review article the ITP syndrome: pathogenic and clinical diversity. Blood 113(26), 6511-6521 (2009).

16. Sakakura M, Wada H, Tawara I et al. Reduced Cd4+Cd25+ T cells in patients with idiopathic thrombocytopenic purpura. Thromb. Res. 120(2), 187-193 (2007).

17. Zhang J, Ma D, Zhu X, Qu X, Ji C, Hou M. Elevated profile of Th17, Th1 and Tc1 cells in patients with immune thrombocytopenic purpura. Haematologica 94(9), 1326-1329 (2009).

18. Hu Y, Ma D, Shan $\mathrm{N}$ et al. Increased number of Tc17 and correlation with Th17 cells in patients with immune thrombocytopenia. PLoS ONE 6(10), e26522 (2011). 
19. Toltl LJ, Nazi I, Jafari R, Arnold DM. Piecing together the humoral and cellular mechanisms of immune thrombocytopenia. Semin. Thromb. Hemost. 37(6), 631-639 (2011).

20. McMillan R. Antiplatelet antibodies in chronic immune thrombocytopenia and their role in platelet destruction and defective platelet production. Hematol. Oncol. Clin. North Am. 23(6), 1163-1175 (2009).

21. Cines DB, Blanchette vs Immune thrombocytopenic purpura. N. Engl. J. Med. 346(13), 995-1008 (2002).

22. Nugent D, McMillan R, Nichol JL, Slichter SJ. Pathogenesis of chronic immune thrombocytopenia: increased platelet destruction and/or decreased platelet production. Br. J. Haematol. 146(6), 585-596 (2009).

23. Vollenberg R, Jouni R, Norris PAA et al. Glycoprotein V is a relevant immune target in patients with immune thrombocytopenia. Haematologica. 104(6), 1237-1243 (2019).

24. McMillan R, Wang L, Tomer A, Nichol J, Pistillo J. Suppression of in vitro megakaryocyte production by antiplatelet autoantibodies from adult patients with chronic ITP. Blood 103(4), 1364-1369 (2004).

25. Cooper N. State of the art - how I manage immune thrombocytopenia. Br. J. Haematol. 177(1), 39-54 (2017).

26. Neunert CE, Cooper N. Evidence-based management of immune thrombocytopenia: ASH guideline update. Hematology Am. Soc. Hematol. Educ. Program. 2018(1), 568-575 (2018).

27. Braselmann S, Taylor V, Zhao H et al. R406, an orally available spleen tyrosine kinase inhibitor blocks fc receptor signaling and reduces immune complex-mediated inflammation. J. Pharmacol. Exp. Ther. 319(3), 998-1008 (2006).

- $\quad$ First-in-human study demonstrating oral bioavailability of R406 and potential for modulating spleen tyrosine kinase activity in human disease. Mechanism of action of R406 is established, with R406 binding to the ATP binding pocket of spleen tyrosine kinase and competitively inhibiting its kinase activity.

28. Valera I, Fernandez N, Trinidad AG et al. Costimulation of dectin-1 and DC-SIGN triggers the arachidonic acid cascade in human monocyte-derived dendritic cells. J. Immunol. 180(8), 5727-5736 (2008).

29. Sanderson MP, Gelling SJ, Rippmann JF, Schnapp A. Comparison of the anti-allergic activity of Syk inhibitors with optimized Syk siRNAs in FcepsilonRI-activated RBL-2H3 basophilic cells. Cell. Immunol. 262(1), 28-34 (2010).

30. Poole A, Gibbins JM, Turner M et al. The Fc receptor gamma-chain and the tyrosine kinase Syk are essential for activation of mouse platelets by collagen. EMBO J. 16(9), 2333-2341 (1997).

31. Law DA, Nannizzi-Alaimo L, Ministri $\mathrm{K}$ et al. Genetic and pharmacological analyses of Syk function in alphaIIb beta3 signaling in platelets. Blood 93(8), 2645-2652 (2017).

32. Clark Ea, Shattil SJ, Ginsberg MH, Bolen J, Brugge JS. Regulation of the protein tyrosine kinase pp72syk by platelet agonists and the integrin alpha IIb beta 3. J. Biol. Chem. 269(46), 28859-28864 (1994).

33. Moroi M, Shinmyozut K, Hospital KC. A patient with platelets deficient. 84, 1440-1445 (1989).

34. Podolanczuk A, Lazarus AH, Crow AR, Grossbard E, Bussel JB. Of mice and men: an open-label pilot study for treatment of immune thrombocytopenic purpura by an inhibitor of Syk. Blood 113(14), 3154-3160 (2009).

- Initial proof-of-concept, open-label, single-arm cohort dose-escalation trial demonstrating a $50 \%$ sustained response rate from patients receiving fostamatinib, with manageable side effects. The activity of fostamatinib was also demonstrated in mouse models of ITP and autoimmune hemolytic anemia.

35. Baluom M, Grossbard EB, Mant T, Lau DT. Pharmacokinetics of fostamatinib, a spleen tyrosine kinase (SYK) inhibitor, in healthy human subjects following single and multiple oral dosing in three Phase I studies. Br. J. Clin. Pharmacol. 76(1), 78-88 (2013).

36. Martin P, Cheung SY, Yen M, Han D, Gillen M. Characterization of the disposition of fostamatinib in Japanese subjects including pharmacokinetic assessment in dry blood spots: results from two Phase I clinical studies. Eur. J. Clin. Pharmacol. 72(1), 61-71 (2016).

37. Martin P, Oliver S, Gillen M, Marbury T, Millson D. Pharmacokinetic properties of fostamatinib in patients with renal or hepatic impairment: results from 2 Phase I clinical studies. Clin. Ther. 37(12), 2823-2836 (2015).

38. Friedberg JW, Sharman J, Sweetenham J et al. Inhibition of Syk with fostamatinib disodium has significant clinical activity in non-Hodgkin lymphoma and chronic lymphocytic leukemia. Blood. 115(13), 2578-2585 (2010).

39. Baluom M, Samara E, Grossbard EB, Lau DT. Fostamatinib, a Syk-kinase inhibitor, does not affect methotrexate pharmacokinetics in patients with rheumatoid arthritis. J. Clin. Pharmacol. 51(9), 1310-1318 (2011).

40. Pine PR, Chang B, Schoettler N et al. Inflammation and bone erosion are suppressed in models of rheumatoid arthritis following treatment with a novel Syk inhibitor. Clin. Immunol. 124(3), 244-257 (2007).

41. Tavlesse $100 \mathrm{mg}$ film-coated tablets SmPC. www.medicines.org.uk/emc/product/11479/smpc.

42. Sweeny DJ, Li W, Clough J et al. Metabolism of fostamatinib, the oral methylene phosphate prodrug of the spleen tyrosine kinase inhibitor R406 in humans: Contribution of hepatic and gut bacterial processes to the overall biotransformation. Drug Metab. Dispos. 38(7), 1166-1176 (2010).

43. Hughes D, Blevins F, Shah B, Sarosiek S, Lerner A, Sloan JM. Real-world experience with fostamatinib in patients with immune thrombocytopenia at an academic medical center. Blood 134(Suppl. 1), 4912 (2019).

44. Clinical trials database: NCT02076399. www.clinicaltrials.gov/ct2/show/NCT02076399. 
45. Clinical trials database: NCT02076412. www.clinicaltrials.gov/ct2/show/NCT02076412.

46. Clinical trials database: NCT02077192. www.clinicaltrials.gov/ct2/show/NCT02077192

47. Bussel J, Arnold DM, Grossbard E et al. Fostamatinib for the treatment of adult persistent and chronic immune thrombocytopenia: results of two Phase 3, randomized, placebo-controlled trials. Am. J. Hematol. 93(7), 921-930 (2018).

-• Results of two Phase 3, randomized, placebo-controlled trials where fostamatinib demonstrated efficacy in adults with chronic immune thrombocytopenia including those who failed to other treatments such as splenectomy, thrombopoietic agents, and/or rituximab. Fostamatinib is a novel approach that targets an important mechanism of ITP pathogenesis.

48. Bussel J, Arnold DM, Duliege AM. Long-term fostamatinib treatment of adults with immune thrombocytopenia during the Phase 3 clinical trial program. Am. J. Hematol. 94, 546-553 (2019).

-. Interim analysis of the open-label extension study (FIT-3) to evaluate the long-term safety and efficacy of fostamatinib. Almost half of the patients achieved an overall response, and most of these maintained their responses for more than 2 years. No new or increased frequency of adverse events were seen up to 31 months of treatment.

49. Duliege A-M, Arnold DM, Boccia R et al. Two-year safety and efficacy outcomes with fostamatinib in adult patients with immune thrombocytopenia (ITP): open-label extension to Phase 3 trial program. Blood 132(Suppl. 1), 736 (2018).

50. McBride A, Nayak P, Kreychman Y, Todd L, Duliege A-M, Mehta AR. Fostamatinib disodium hexahydrate: a novel treatment for adult immune thrombocytopenia. Am. J. Managed Care. 25(19), S347-358 (2019).

51. Boccia R, Boxer MA, Ghanima W et al. Fostamatinib is an affective second-line therapy in patients with immune thrombocytopenia. Br.J. Haematol. (2020). doi:10.1111/bjh.16959.

-. Post hoc analysis compared patients who received fostamatinib as second-line therapy in Phase 3 trials of adults with immune thrombocytopenia versus third-or-later-line therapy. Fostamatinib was more effective as second-line than third-or-later-line therapy.

52. Rodeghiero F. Is ITP a thrombophilic disorder? Am. J. Hematol. 91(1), 39-45 (2016).

53. Altomare I, Markovtsov VV, Todd L et al. Potential anti-thrombotic effect without accompanying hemorrhage with fostamatinib use in patients with immune thrombocytopenia. Blood 134(Suppl. 1), 4889 (2019).

-• Syk inhibition likely reduces the incidence of thromboembolic events by abrogating the GPVI and CLEC-2 pathways in platelets. These mechanisms potentially explain why ITP patients treated with fostamatinib are protected from developing thromboembolic events despite often substantial platelet increases. Thus, Syk inhibition in ITP may simultaneously decrease platelet destruction (thereby increasing platelet count) and decrease the incidence of thromboembolic events. 